\title{
SE AS PULGAS DESENVOLVESSEM UM RITO, ELE ESTARIA RELACIONADO AO CÃO
}

\author{
If fleas developed a rite, It would \\ be related to the dog
}

João José Rodrigues Lima Almeida

Doutor em Filosofia pela Universidade Estadual de Campinas (Unicamp), professor substituto da Unesp/Araraquara, São Paulo, SP - Brasil, e-mail: limalme@ uol.com.br

\section{Resumo}

Este artigo destaca um conjunto de observações de Wittgenstein sobre textos de $O$ Ramo de Ouro, de James Frazer, situa essas observações dentro do contexto de criação de um enquadramento conceitual para a sua renovada visada filosófica depois do retorno a Cambridge, entre 19291932, e demarca o valor ritualístico do método gramatical de filosofia.

Palavras-chave: Wittgenstein. Gramática. Ritual. Método da Filosofia. 


\section{Abstract}

This article highlights a set of Wittgensteinian remarks on James Frazer's texts found in The Golden Bough, put it inside the context of creation of a conceptual framework for his renewed philosophical approach after his return to Cambridge, a period comprehended between 1929-1932, and delimits the ritualistic value of his grammatical method of philosophy.

Keywords: Wittgenstein. Grammar. Ritual. Method of Philosophy.

Neste $\operatorname{artigo}^{1}$ gostaria de desenvolver algumas breves reflexões acerca da concepção de gramática como um ritual. Tomo por base o fato de que se o interesse de Wittgenstein pela linguagem mudou de foco em 1930, passando da atividade de esclarecimento possibilitada pelo conceito de forma lógica para a investigação do emprego da linguagem no interior de uma forma de vida, o período de 1929 a 1932, subsequente ao seu retorno à filosofia, teve de ser extremamente profícuo e produtivo. Pois essa fase demandava tanto uma revisão dos antigos conceitos tractarianos quando a criação de um enquadramento completamente novo, adaptado à retomada do interesse filosófico pela perspectiva pragmática. Se a primazia ainda continuava sendo a da ética, os conceitos eram tratados agora como "objetos de comparação", e não mais como "objetos doutrinários". E o foco, não mais o esclarecimento da linguagem mas a autoterapia, indica que a nova atividade filosófica é a de dissolução de dogmatismos. A investigação dos aspectos ritualísticos da gramática está localizada precisamente neste contexto. Uma concepção que nasceu no centro de um conjunto de reflexões acerca da teoria evolucionista do antropólogo inglês James Frazer. O que pretendo, então, indicar neste artigo é um possível ganho teórico de Wittgenstein no início dos anos $30 \mathrm{com}$ as suas reflexões sobre $O$ Ramo de Ouro, de Frazer.

Utilizo as seguintes abreviações para os textos de Wittgenstein: MS (manuscrito do Nachlass), TS (datiloscrito do Nachlass), ORO (Observações Sobre o Ramo de Ouro), IF (Investigações Filosóficas,), LC (Lectures and Conversations on Aesthetics, Psychology \& Religious Beliefs), CV (Cultura e Valor), BT (Big Typescript), VW (The Voices of Wittgenstein, The Vienna Circle -Ludwig Wittgenstein and Friedrich Waismann). Todas as traduções são de minha responsabilidade. 


\section{INTRODUÇÃO}

O conjunto de reflexões filosóficas denominadas como Observações Sobre O Ramo de Ouro de Frazer ${ }^{2}$ (WITTGENSTEIN, 2007) reúne as variações do pensamento de Wittgenstein em torno da obra do influente antropólogo inglês do começo do século XX. Um conjunto que, na verdade, é uma seleção editorial, pois essas observações se encontram nos seus manuscritos e textos datilografados misturadas no meio de muitos outros temas de natureza diversa. As críticas do filósofo a Frazer estão entremeadas pelo tratamento de aspectos da linguagem, da matemática, da lógica, do simbolismo, do pensamento, da compreensão, dos fenômenos etc. Por isso, conquanto se possa separar claramente os temas entre si, como tradicionalmente tem sido feito na publicação do seu legado literário, por outro lado não se pode denegar que os temas se atravessam continuamente em inúmeros e múltiplos pontos. O que os editores usualmente entregam ao público é somente uma compilação cujo solo originário deve ser considerado sempre com cuidado, é um conjunto de reflexões cuja paisagem naturalmente entrecruzada deve ser sempre levada em conta, cuja proposição reclama incessantemente um segundo olhar para os manuscritos e para o estilo que caracteriza a natureza da investigação e do pensamento de Wittgenstein. Trata-se aqui, evidentemente, de lembrar o próprio espírito do texto sobre Frazer, evocado em um dos seus enunciados: "Eu tenho que mergulhar repetidamente na água da dúvida" (TS, 211, p. 313; ORO, p. 192). Um efeito que se vê enormemente facilitado pelo estilo entrecruzado e iterativo das observações filosóficas wittgensteinianas.

É nesta terra arada e preparada, "Nós temos que arar toda a extensão da linguagem" (TS, 211, p. 320; ORO, p. 199), que encontramos esta observação entre parênteses: "(Se as pulgas desenvolvessem um rito, ele estaria relacionado ao cão)" (MS, 110, p. 298; ORO, p. 204). Wittgenstein estava comentando a seguinte passagem de Frazer, sobre rituais mágicos de povos europeus relacionados ao carvalho:

2 Texto por mim traduzido em edição bilíngue, com anotação das fontes originais e variações de palavras, e que pode ser encontrado na Revista digital AdVerbum, v. 2, n. 2, p. 186-231, 2007. $<$ www.psicanaliseefilosofia.com.br/adverbum/Vol2_2/observacoes_ramo_de_ouro.pdf $>$ com download livre. 
Esta peculiaridade da árvore tem sido estabelecida de maneira similar por séries de observações instituídas em anos recentes por pesquisadores científicos que não as sustentam com teorias mitológicas. Conquanto possamos explicá-la, seja pela mais fácil passagem de eletricidade pela madeira do carvalho do que por outra madeira, seja de outro modo, o fato em si pode ter atraído a atenção de nossos rudes antepassados, que habitavam em vastas florestas que então cobriam uma grande parte da Europa; e eles podiam, naturalmente, dar conta disso, à sua maneira religiosa simples, supondo que o grande deus-céu, a quem eles adoravam e cuja terrível voz eles ouviam no ribombar do trovão, amava o carvalho acima de todas as árvores do bosque, e muitas vezes descia para ele da nuvem escura no raio de um relâmpago, deixando um sinal da sua presença ou da sua passagem no tronco rachado e escurecido, e na folhagem destruída. Daí em diante, essas árvores seriam circuladas por um nimbo de glória como assentos visíveis do deus-céu trovejante (FRAZER, 1940, p. 708-709).

Para o filósofo, ao revés do que supõe Frazer, não há realmente nenhum fundamento para que certas raças humanas estivessem unidas ao carvalho (MS, 110, p. 298; ORO, p. 204). A explicação de Frazer está na realidade atribuindo a elementos externos, a fundamentos em si mesmos inexplicados, a responsabilidade pelo comportamento dos selvagens. Esses fundamentos inexplicados não se comprovam senão na sua própria intenção de retratar povos selvagens como dotados de pensamento mágico. Mas se quisermos fundamentos inexplicáveis, parece ser bem mais natural e bem mais fácil pensar que o homem e o carvalho estiveram unidos ali desde a sua origem, que a sua relação é imediata, interna, que eles surgiram juntos naquele ambiente, como a pulga e o cão, e que isto, simplesmente, se dá assim, sem explicação. Atribuir-lhes um pensamento mágico, uma maneira ingênua de articular as relações de causa e efeito é explicar o seu comportamento tomando como base o nosso. Pela descrição gramatical, que em Wittgenstein é uma filosofia do ato (um ato, lembremos, é uma realização espontânea da vontade, sem fundamento), aqueles homens e mulheres estariam, simplesmente, celebrando rituais.

Ver a atividade daquelas pessoas como cumprimento de ritual em vez de comportamento guiado por crenças tem algumas implicações filosóficas cruciais. Vejamos algumas delas. 


\section{A magia, o simbolismo e a linguagem}

Quando Wittgenstein observa que "[...] a magia sempre repousa sobre a idéia do simbolismo e da linguagem" (TS, 211, p. 316; ORO, p. 195), pensa na linguagem como parte de uma atividade na qual ela é uma ferramenta. Isto é, Wittgenstein está tentando capturar ainda a forma da linguagem, mas não mais a forma por si mesma, tal como o fazia o jovem Ludwig, escritor do Tractatus. Trata-se agora do uso da forma (LC, p. 2). Se atentamos para a forma em seu uso, e não somente para o conteúdo, que fazem os seres humanos que adoram o carvalho? A pergunta, encaminhada nesta direção, tem o efeito de deixar muito mais claro o que há de comum e o que há de diferente entre nós e eles. Este uso da forma, ou a pergunta pela forma nas suas aplicações, no seu emprego, é o que Wittgenstein chama de "observações gramaticais": "Nossa investigação (Untersuchung) não é dirigida aos fenômenos, mas ao que se poderia chamar de 'possibilidades' dos fenômenos" (IF, § 90).

O ponto em questão não é exatamente a crença envolvida naquela espécie de ritual, fundamento sobre o qual Frazer, não sem propósitos interessados, teima em se agarrar, mas a atividade simbólica desempenhada naquele contexto. Enquanto Frazer tenta enxergar e capturar a crença, o elemento psicolinguístico ou a "atitude proposicional", como mais tarde denominou a filosofia da linguagem, encarregada em grande parte pela formulação de juízos acerca da realidade, o verdadeiro ou o falso - e aquela é claramente falsa -, Wittgenstein corre para os elementos que estruturam as crenças, isto é, a questão do sentido, que é o sustentáculo imanente à experiência. Como tal, ele não é nem externo, nem transcendente e nem se coloca como um fundamento propriamente dito. Não se tratam de princípios, fatos ou provas: nosso autor busca, à diferença de Frazer, a armação simbólica mediante a qual um juízo pode ser formulado ou em conformidade com a qual uma crença pode se organizar. Como sabemos, para Wittgenstein, depois de 1930, nada sobrou de metalógico escondido por detrás da linguagem: “Assim como não há metafísica, não há metalógica. A palavra 'compreender', a expressão 'compreender uma proposição' não é metalógica, mas uma expressão como qualquer outra da linguagem" (MS, 110, p. 189). Uma crença, portanto, é dependente do sentido, da forma pela qual foi articulada no interior de uma atividade.

Nas Observações Sobre o Ramo de Ouro de Frazer, a magia, como reação imediata, como atitude, é a exteriorização de um desejo. 
Como crença, ela pode ser outra coisa, mas sempre subordinada às suas regras gramaticais. Porém, como desejo, "a apresentação de um desejo é, eo ipso, a apresentação da sua realização" (TS, 211, p. 316; ORO, p. 196). Por isso, a única coisa que podemos entender diante de um ritual é que ele visa somente a sua satisfação. Ele não visa a sua verdade, que pouco importa diante disso tudo. E, no fundo, um ritual não visa absolutamente nada: "nós agimos assim mesmo e nos sentimos satisfeitos" (TS, 211, p. 316; ORO, p. 195).

A ideia do gramatical, portanto, é a ideia do simbolismo e da linguagem, mas compreendida não mais de maneira abstrata, como uma forma lógica, mas compreendida como ato. Forma, no começo dos anos 30, passou a significar uma atividade: quais são as regras mediante as quais uma atividade como aquela pode ser compreendida? Quais são as condições de significância do ato? Como se organiza ali, naquela atividade, o sentido que permite, entre muitas outras coisas, formular não só crenças, juízos, asserções, mas também desejos, expectativas, intenções, propósitos?

Trata-se de "história natural dos homens, não psicologia" (MS, 156, p. 54v), de como eles fazem as coisas de maneira simbólica, e como no uso da forma todas as dificuldades do nosso entendimento se dissolvem.

\section{Justiça diante dos fatos}

Há um espírito nos textos de crítica a Frazer que não deveria, sob hipótese alguma, ser negligenciado ou deixar-se perder em meio a outras considerações sobre as suas observações. E talvez esse espírito esteja expresso na frase: "Nada é tão difícil quanto justiça diante dos fatos" (TS, 211, p. 319; ORO, p. 198). Essas observações são, antes de tudo, uma luta pelo aspecto ético. Mas não uma ética que preconiza o que devemos fazer sob qualquer princípio moral ou sequer de razão. Trata-se de uma ética silenciosa e negativa, que não deixa, por isso mesmo, de ser árdua. Não apenas quebrar ídolos, mas também como cuidar da dissolução de dogmatismos de uma maneira eticamente consequente com a sua própria atividade. A solução é nada sugerir, senão apenas indicar o que o paciente já pressupõe em seus atos. Como colocar isso em prática? Wittgenstein, nessa época, vislumbrou uma possibilidade: aplicar o método filosófico, multiplicando as analogias, recorrendo a exemplos, comparações, e tentando devolver, assim, as palavras do seu emprego metafísico para o quotidiano (IF, § 116). 
A injustiça tem o seu ambiente tóxico (seus nutrientes) engendrado por toda espécie de confusões conceituais. Essas confusões fazem com que as palavras abandonem o seu uso habitual e adquiram um falso caráter de profundidade (IF, § 111). O método filosófico é chamado a aplicar-se nesses casos: as palavras, no seu berço gramatical, têm todo o sentido pressuposto no seu uso, e nenhum a mais. O gramatical, o uso da palavra, é o pano de fundo sob cujo contraste nenhum truque de prestidigitação poderá favorecer o interesse de alguns em detrimento dos demais.

Bertrand Russell:

É assim que Wittgenstein fala da injustiça de Jean Nicod e de

Quando descrevo certos jogos de linguagem simples, não é o caso de se descrever com eles os processos reais da nossa linguagem desenvolvida - o que só levaria a injustiças (Nicod \& Russell). Pelo contrário, deixamos os jogos simplesmente como estão. Eles só devem irradiar o seu efeito clarificador sobre os nossos problemas (MS, 115, p. 81).

O que parece injusto para Wittgenstein é utilizar o conceito de jogo de linguagem como alguma coisa a mais do que mero objeto de comparação. Spengler, por exemplo, pretendeu que a sua "fisiognomia" fosse uma espécie de ideal de ciência para a história, compreendida como disciplina, e, nisso, também cometeu injustiça:

Só podemos evitar a injustiça - ou vacuidade em nossas afirmações, quando colocamos o ideal como aquilo que ele é, a saber, como objeto de comparação - por assim dizer, como padrão de medida - na nossa reflexão, \& não como o preconceito ao qual tudo deve se conformar. Este é na verdade o dogmatismo no qual a filosofia tão facilmente pode decair. Mas então qual é a relação entre uma reflexão como a de Spengler $\&$ a minha? A injustiça de Spengler: o ideal nada perde da sua dignidade se ele for colocado como princípio da forma da reflexão. Uma boa unidade de medida (CV, p. 30-31).

O que presenciamos em Frazer é exatamente isso: um ideal ao qual tudo deve se conformar. Para Frazer, todos os seres humanos se encaixam num padrão evolutivo em torno da ideia de causa e efeito e de racionalidade lógica: em nossa infância ainda acreditamos na eficácia da magia, depois, na adolescência antropológica, viramos religiosos e personificamos a razão em deuses, e finalmente nos tornamos científicos na fase amadurecida e europeia do homem do século XX. Frazer trata o 
gramatical como se fosse ciência, promovendo uma espécie de confusão conceitual, e favorecendo a indicação do típico cientista inglês do século $\mathrm{XX}$ como ideal de vida ao qual tudo deve se conformar.

Através dessa confusão, a injustiça de Frazer aparece no fato de que projeta sobre o outro algo que é nosso como se não fosse nosso. Frazer utilizava-se do modo de vida dos selvagens como prova da superioridade do pensamento lógico e científico. Os selvagens seriam tão equivocados em seu pensamento mágico e religioso quanto as crianças na manifestação onipotente do seu desejo, mas semelhantes a nós em potencial. Wittgenstein mostra em suas Observações Sobre O Ramo de Ouro, que essa superioridade é falsa, pois se por um lado temos um pensamento lógico e científico, por outro lado ainda convivemos perfeitamente com formas próprias de superstição, de mágica e de religião: beijamos a foto da pessoa amada, apertamos os lábios enquanto torcemos pela realização de uma expectativa, confessamos nossos pecados, tememos os relâmpagos e trovões, tiramos o chapéu para saudar um amigo ou lhe apertamos uma das mãos. O próprio autor do Tractatus começou a falar sobre o "mundo" porque procurava encantar com as suas palavras algo de mais alto (MS, 110, p. 178; ORO, p. 192). A metafísica, um hóspede aparentemente incômodo, convive silenciosamente conosco sem deixar-se muitas vezes notar. A primeira atitude ética a ser tomada é reconhecer precisamente este fato, não omiti-lo como se nós vivêssemos num estado superior de pureza:

Creio agora que seria correto iniciar um $<$ meu $>$ livro sobre com observações sobre a metafísica como uma espécie de magia.

Ao fazê-lo, no entanto, eu não poderia falar a favor da magia nem fazer troça dela.

A profundidade da magia teria que ser mantida. - Sim, pois a eliminação te toda da magia teria aqui o caráter da própria magia (MS, 110, p. 177; ORO, p. 192)

E aqui, sim, a profundidade gramatical não se confunde com uma aparência de profundidade decorrente de más interpretações das formas da nossa linguagem. O comportamento dos selvagens e dos povos chamados primitivos nada tem de semelhante ao do cientista em busca de causas ou de explicações hipotéticas para os fenômenos. Compreender seus rituais em termos de crenças outorga injustamente à forma da linguagem do observador evolucionista uma falsa aparência de profundidade. 


\section{A metafísica da gramática ou a gramática como metafísica}

O mesmo tipo de crítica endereçada a Frazer, Wittgenstein já havia feito um ano antes a Ernest Renan, um historiador positivista, que dizia em seu livro História do Povo de Israel que povos primitivos se impressionam com fatos como o nascimento, a doença, a morte, o delírio, a catalepsia, o sono, os sonhos, que são fenômenos que têm suas causas, segundo o citado historiador, na nossa própria organização. Wittgenstein destaca frente a Renan que fenômenos como estes são na realidade fatos do dia-a-dia, até certo ponto corriqueiros, comuns, e se povos primitivos deveriam se impressionar com eles, tanto mais os cães e os macacos $(\mathrm{CV}$, p. 7). Obviamente, não se encontra nenhuma razão para tais conclusões, senão na própria intenção oculta do historiador, que se comporta ele mesmo como a imagem do primitivo que projeta em seus textos, impressionado pelas explicações causais.

Mas se não é a explicação em termos de causa e efeito que nos impressiona, o que realmente nos surpreende, arrebata e comove? Por que povos primitivos dançam para que chova? Por que matam seus inimigos em efígie e não de corpo presente? Por que matam o rei no auge da sua juventude e do seu vigor? Segundo Frazer, porque essas pessoas acreditavam que a dança provocaria a chuva no árido e quente deserto, ou acreditavam que seus inimigos morreriam por procedimentos mágicos, ou porque matando o rei-sacerdote tão cedo era o único meio de conservar fresca a sua alma (TS, 211, p. 314; ORO, p.193). Mas é realmente uma teoria que explica o comportamento dos primitivos, ou, como retruca Wittgenstein em direção decididamente divergente, o conceito e o comportamento são na realidade dados juntos?

E aqui já opera a concepção gramatical em Wittgenstein: existe uma relação interna e imediata, sem qualquer elemento explicativo externo a ela, seja em termos mentalistas, materialistas ou ocasionalistas, que reúne pensamento, experiência, emoção, atividade e simbolismo no mesmo pacote, atuando em conjunto para determinados propósitos, e que somente se compreendem em sua inter-relação no interior das formas de vida. Essa relação interna e imediata, aprendida pelas pessoas dentro das suas culturas, se diferencia de outro tipo de relações que estabelecemos com a experiência, as externas, que são as entretidas nas teorias científicas em termos de causas e efeitos. A diferença entre uma e outra é que a primeira é fechada e se justifica, até um determinado ponto, o ponto em que elas 
são um ato (IF, § 211), em termos de razões, e a segunda é aberta e não se justifica senão na extensão infinita de uma rede causal.

Uma gramática é uma metafísica operativa, não doutrinária nem científica. Organiza objetos em termos de amostras ou paradigmas (o metro padrão, a cor azul) que são seus meios de apresentação, estabelece uma correlação com outros objetos ("tal pedaço de madeira mede um metro"; "o branco é mais claro que o preto"), e autoriza transformações sobre eles (subdividir o sistema de medida, misturar cores). As regras gramaticais aprendidas no interior de uma cultura normatizam essas relações, que se transformam numa segunda natureza, incorporam-se em hábitos, e fazem com que atos se desempenhem sempre de acordo com uma regra.

Mas, por outro lado, tampouco devemos deixar de notar que a própria filosofia de Wittgenstein, uma atividade antes que um corpo de doutrinas, é uma gramática ou uma metafísica operativa. Portanto, duas coisas distintas, mas conectadas, estão dadas nessas reflexões críticas sobre a antropologia evolutiva: a primeira, é a de que tanto o procedimento de Frazer como o dos selvagens são gramaticais; a segunda, é que podemos criar uma gramática para, precisamente, esclarecer esse ponto. Exatamente por este caráter, um caráter sobretudo ético, é que nosso filósofo concebeu, em meio às suas observações sobre Frazer, aquele que seria o seu método da filosofia, a übersichtliche Darstellung.

A ideia surge quando Wittgenstein comenta que as explicações de Frazer são tão selvagens ${ }^{3}$ quanto a maioria dos seus selvagens (TS, 211, p. 321; ORO, p. 200). Não se diferenciam das deles sob o ponto de vista gramatical, já que o seu procedimento consiste em ser nada mais do que uma organização dos dados empíricos e conceituais para atuar em um sentido determinado, uma sinopse que se resume numa imagem geral, a evolutiva, mas que poderia ter sido um arranjo com outro tipo de conformação. A coletânea de fatos frazeriana poderia ter adotado por exemplo a ideia de uma "lei secreta" subjacente aos fatos, tal como a morfologia das plantas segundo a visão de Goethe, ou poderia ter sido montada pelo esquema de uma cerimônia religiosa, ou poderia ter sido tão-somente o mero agrupamento dos materiais factuais - o que Wittgenstein já vinha denominando há algum tempo como "apresentação panorâmica" (übersichtliche Darstellung). E então vem em seguida no

3 Wittgenstein anota essa palavra em inglês (savage), porque a mimetização comporta claramente aqui uma ironia. 
manuscrito (MS, 110, p. 256-257), muito embora no datiloscrito correspondente essas observações tenham sido colocadas em páginas bem separadas (TS, 211, p. 281-282), a apresentação do método da filosofia como uma gramática:

O conceito de apresentação panorâmica tem para nós a mais fundamental importância. Ele marca a nossa forma de apresentação, a maneira como nós vemos as coisas. [...] Esta apresentação panorâmica proporciona o compreender // a compreensão //, que consiste precisamente em "ver as concatenações". Daí a importância do encontrar os elos intermediários (ORO, p. 200-201).

A "apresentação panorâmica" é apresentada como "método da filosofia" tanto nos ditados a Waismann quanto no Big Typescript (TS, 213, p. 417; TS, p. 306-307), e alcança a sua definitiva consignação nas IF $\S 122$. Trata-se do procedimento terapêutico de provocação do olhar para outro ponto de vista através da multiplicação de analogias e de exemplos que dissolvem a rigidez dogmática de interpretações fechadas que se enraizaram nas formas gramaticais. O método é operativo sem ser diretivo ou sugestivo, e apenas pretende estender o olhar do paciente para a maneira como o seu pensamento organizou-se em ligação com a experiência e com um certo propósito ou intenção. O método é montado também de acordo com os mesmos parâmetros metafísicos que as outras gramáticas, porém sem intenções cognitivas ou doutrinárias.

\section{Gramática como ritual}

Por que então, finalmente, essas pessoas dançam, matam os seus inimigos em efígie ou sacrificam o rei no seu auge? Certamente não por causa de crenças ou opiniões, mas como parte de um ritual que se satisfaz por si mesmo:

[...] poder-se-ia começar um livro de antropologia assim: quando se considera a vida e a conduta do homem sobre a terra, é possível ver que, além do que se pode denominar de atividades animais, a alimentação etc., etc., etc., há também realizações que carregam um caráter totalmente outro // específico// e que se poderiam denominar ações rituais (TS, 211, p. 319-320; ORO, p. 198). 
Descrevendo esses rituais, um pouco à maneira do etólogo, mais do que do antropólogo cientista, podemos encontrar, ou pelo menos tentar esclarecer, as semelhanças e as diferenças entre nós e eles.

Por outra parte, é também no sentido ritualístico que podemos entender agora o comentário sobre a relação entre a pulga e o cão colocado entre parênteses no texto. A analogia propõe-se como uma aplicação do método filosófico. Não é uma informação nem um dado cognitivo que é posto, mas uma decisão a respeito da filosofia vivida como uma atividade. O que faz Wittgenstein com a imagem da relação entre a pulga e o cão? Ela está sendo aplicada como objeto de comparação para ampliar o nosso olhar e podermos enxergar que a relação que o homem estabelece com a experiência enquadra-se de modo interno com a sua história natural, e não como um fundamento transcendente, tal como o psicológico: “[...] o característico da ação ritual é não ter nenhum parecer, nenhuma opinião, como se ela fosse verdadeira ou falsa, conquanto uma opinião - uma crença - possa ela mesma também ser ritual, pertencer a um rito" (TS, 211, p. 320; ORO, p. 199).

Wittgenstein tenta persuadir seu eventual leitor, mas também exerce por este meio a sua autoterapia, de que explicar um costume é equivocado no sentido suposto de "neutralidade objetiva" guardado pela palavra "explicar": tudo o que conseguimos fazer, por conta de ser a atividade gramatical e não científica, é tornar esses costumes plausíveis para os homens que pensam de modo semelhante a nós (TS, 211, p. 313; ORO, p. 193). Somos, assim, persuadidos a viver a filosofia não mais como teoria, mas como atividade gramatical. Na explicação gramatical, ou seja, numa descrição, é diferente: organizamos tudo aquilo que já se sabe, e nada acrescentamos: [...] só se tem que organizar corretamente o que se sabe, e nada acrescentar, e vem por si mesma a satisfação a que se aspira pela explicação. [...]. Aqui só se pode descrever e dizer: assim é a vida humana (TS, 211, p. 314, 315; ORO, p. 194).

A filosofia, à moda de Wittgenstein, deixa tudo como está. Mas agora, convertidos e não convencidos, vemos claramente, em extensão panorâmica, numa visada perspícua que estende diante de nós todas as correlações estabelecidas na cultura entre a experiência, a intenção, a história natural e a atividade, o que fazem aquelas pessoas, o que pode estar envolvido nos seus atos, e como nos diferenciamos deles. O interesse não é mais cognitivo, mas ético. Podemos perfeitamente decidir então em relação ao ato. Ato que em si mesmo não se explica: "Também esta se pode 'explicar' e não se pode explicar." (TS, 211, p. 316; ORO, p. 195). 
O método da filosofia, tomado como um rito gramatical como qualquer outro rito, satisfaz-se por si mesmo, no cumprimento de suas regras, na observância estrita dos seus valores, e desperta-se no espírito de uma veneração e ao redor de fenômenos que nada têm em si de especial, mas que, para aqueles que com eles se envolveram de alguma forma, adquirem um caráter misterioso e profundo:

Pois, nenhum fenômeno é por si especialmente misterioso, mas todos podem vir a sê-lo para nós, e este é precisamente o característico no despertar do espírito do homem, que para ele um fenômeno venha a ter um significado. Poder-se-ia quase dizer que 'o homem é um animal cerimonial'. Isto é talvez em parte falso, em parte absurdo, mas aqui também há algo de correto (TS, 211, p. 319; ORO, p. 198).

A filosofia como atividade terapêutica não só nos esclarece que a relação entre os fatos e os seus símbolos é visceral, instintiva, reativa, não exclusivamente intelectual, que se trata muito mais de ato que de pensamento (sem que do ato esteja necessariamente destituído um pensamento), que uma filosofia e seus conceitos, enfim, são gramaticais, mas também pretende nos infundir a gramática da sua filosofia, um espírito, uma devoção, uma veneração que nos desperta e nos induz a evitar a injustiça de tratar conceitos filosóficos como descobertas científicas e a devolver as palavras do seu uso explicativo para o ritual.

\section{REFERÊNCIAS}

BAKER, G. (Ed.). The voices of Wittgenstein: the Vienna circle: Ludwig Wittgenstein and Friedrich Waismann. Trans. Gordon Baker, Michael Mackert, John Connolly and Vasilis Politis. London: Routledge, 2003.

FRAZER, J. G. The golden bough: a study in magic and religion. New York: The Macmillan Company, 1940. Publicado originalmente em 1922.

WITTGENSTEIN, L. Lectures and conversations on aesthetics, psychology \& religious belief. Oxford: Blackwell, 1966 .

Tractatus logico-philosophicus. Tradução de Luiz Henrique Lopes dos Santos. São Paulo: EDUSP, 1993. Logisch-Philosophische Abhandlung. 
Culture and value. Tradução de Peter Winch. Oxford: Blackwell, 1998. Vermischte Bemerkungen.

Wittgenstein's Nachlass: the bergen electronic edition. Oxford: Oxford University Press, 2000.

Philosophische untersuchungen/philosophical investigations. Tradução de G. E. M. Anscombe. Oxford: Blackwell, 2001.

. The big typescript (TS 213). Edited and translated by Luckhardt, C. Grant and Aue, Maximilian A. E. Oxford: Blackwell, 2005.

. Observações sobre o ramo de ouro de Frazer/Bemerkungen über Frazers The golden bough. Tradução de João José R. L. Almeida. Revista Digital AdVerbum, v. 2, n. 2, p. 186-231, 2007. Disponível em: <www.psicanaliseefilosofia.com.br/ adverbum/Vol2_2/observacoes_ramo_de_ouro.pdf>. Acesso em: 11 jun. 2008.

Recebido: 10/12/2008

Received: $12 / 10 / 2008$

Aprovado: 04/03/2009

Approved: 03/04/2009 